ARTICLE HISTORY: Received: October 12, 2021 Accepted: December 06, 2021 Published: December 13, 2021

ОЗДОРОВЛЕНИЕ ДЕТЕЙ И ПОДРОСТКОВ АСТРАХАНСКОЙ ОБЛАСТИ

Сибирякова Н.В. ${ }^{1}$, Ширинова 3.P. ${ }^{2}$

${ }^{I}$ ФГБОУ ВО Астраханский ГМУ Минздрава России, Астрахань, Россия

1. ГББУЗ АО ГП №5 «ДПО №1», МБОУ «Средняя общеобразовательная школа №39»,

2. Астрахань, Россия

\title{
WELLNESS OF CHILDREN AND ADOLESCENTS ASTRAKHAN REGION
}

\author{
Sibiryakova N.V. ${ }^{1}$, Shirinova Z.R. ${ }^{2}$ \\ ${ }^{1}$ Astrakhan State Medical University, Russia, Astrakhan \\ ${ }^{2}$ state health institution of the Astrakhan region polyclinic №1 «Children department polyclinic №1》 \\ in the clinic, "Secondary School №39", \\ Russia, Astrakhan
}

\begin{abstract}
Аннотация. Актуальность данной работы определяется фиксирующимся в последние годы снижением физических возможностей подрастающего поколения, увеличением частоты встречаемости острых и хронических заболеваний, что обуславливает необходимость формирования и повышения эффективности оздоровительных мероприятий. Изучено влияние кратковременного отдыха и эффективность оздоровления на соматометрические и физиометрические показатели детей. Обследованы 201 человек в возрасте 7 - 15 лет, находившиеся на период отдыха в детском оздоровительном центре (ДОЦ). Анализ соматометрических и физиометрических показателей детей в динамике пребывания в ДОЦ в течение недели без положительной динамики, что свидетельствует, что такие смены следует считать не оздоровительными, а сменами для организации отдыха детей.

Annotation. The relevance of this work is determined by a decrease in the physical capabilities of the younger generation that has been recorded in recent years, an increase in the incidence of acute and chronic diseases, which necessitates the formation and improvement of the effectiveness of health-improving measures. The influence of shortterm rest and the effectiveness of health improvement on the somatometric and physiometric indicators of children has been studied. Examined 201 people aged 7 - 15 years, who were for a period of rest in the children's health center (DOC). Analysis of the somatometric and physiometric indicators of children in the dynamics of staying in the preschool center for a week without positive dynamics, which indicates that such shifts should be considered not health-improving, but shifts for organizing children's recreation.
\end{abstract}

Ключевые слова: детский оздоровительный центр, оздоровление детей и подростков, отдых.

Key words: children's health center, health improvement for children and adolescents, rest.

Актуальность. Здоровье детей составляет фундаментальную основу для формирования потенциала здоровья общества в целом. Значительные учебные нагрузки, несбалансированное питание и другие неблагоприятные факторы приводят к напряжению эмоциональной сферы ребенка, истощению адаптационных резервов, снижению функциональных возможностей организма, что в большей степени проявляется в конце учебного года. Одной из актуальных проблем медицины и образования является вопрос отдыха и оздоровления детского населения $[1,2,4,5,8,9]$.

Отдых и оздоровление детей - совокупность мероприятий, обеспечивающих охрану и укрепление физического и психического здоровья, профилактику заболеваний, развитие творческого и интеллектуального потенциала.

Лечебно-оздоровительные мероприятия включали соблюдение режима дня, рациональное питание, закаливающие процедуры (воздушные ванны, купание в бассейне), комплекс физических упражнений проводился ежедневно $[3,6]$.

Целью нашего исследования явилось изучение эффективности оздоровления детей и подростков Астраханской области.

Материалы и методы. Исследование осуществлено в соответствии с Хельсинкской декларацией Всемирной медицинской ассоциации «Этические принципы проведения научных медицинских исследований с участием человека» с поправками 2000 г. и «Правилами клинической практики в Российской Федерации», утвержденными Приказом Минздрава РФ от 19.06.2003 № 266. Обследованы дети (I, II и III группы здоровья) в возрасте 7-15 лет, пребывающие в период отдыха в детском оздоровительном центре (ДОЦ) «им. А.С. Пушкина». 
Для комплексной оценки эффективности оздоровления детей в лагере в первый день смены, а также на седьмой день, проводился медицинский осмотр всех отдыхающих с использованием различных методов исследования.

С помощью стандартных методик изучались следующие показатели: рост, масса, мышечная сила кистей, жизненная емкость легких (ЖЕЛ).

Результаты и их обсуждение. Нами проанализирован оздоровительный эффект пребывания 201 детей в ДОЦ за период с 31.10 по 06.11.2021 года. Из них: девочек 117 чел., мальчиков - 84 чел. За единицу наблюдения взята продолжительность оздоровления детей в течение одной смены.

По данным осмотра преобладающими в структуре заболеваемости являются болезни желудочно-кишечного тракта $(6,0 \%)$, зрения - $(5,5 \%)$, опорно-двигательного аппарата $(4,0 \%)$ и др. За неделю не было зарегистрировано обострения хронических заболеваний у детей, групповых инфекционных заболеваний и пищевых отравлений.

Одним из важнейших критериев оценки гармоничного развития ребенка являются показатели мышечной силы. Развитие мышечной системы благоприятно влияет на все системы организма [7].

В начале смены средние показатели физического развития (ФР) выявлены у 173 (86\%). Отклонения в массо-ростовых показателях встречаются у $14 \%$ школьников, которые в основном обусловлены дисгармоничностью в развитии за счет дефицита массы тела (6\%) и избытка массы тела (4\%), за низкого роста тела $(2 \%)$ и высокого роста тела (2\%).

За время отдыха и оздоровления массу тела прибавили 100 детей на 0,2- 0,5 кг.

Исследования силы мышц проводилось при помощи кистевой динамометрии. На начало смены у детей были следующие значения показателя динамометрии: 74,6\% средние, выше средних 2,5\%, ниже средних $15,4 \%$ и низкие $7,5 \%$. У двоих детей с низкими показателями к концу смены улучшились результаты.

В результате анализа спирометрии: на начало смены у $82,1 \%$ детей ЖЕЛ соответствовала нормальным показателям и 2,5\% детей - высоким. На момент отъезда отмечается сдвиг показателей ЖЕЛ в положительную сторону у $4 \%$ детей.

Таким образом, анализ соматометрических и физиометрических показателей детей в динамике пребывания в ДОЦ в течение недели без положительной динамики, что свидетельствует, что такие смены следует считать не оздоровительными, а сменами для организации отдыха детей.

Выводы. Полученные данные подтверждают значимость фактора продолжительности смены в эффективности оздоровления, служат обоснованием целесообразности продолжительности оздоровительной смены не менее 21 дня.

\section{ЛИТЕРАТУРА}

1. Антонова А.А., Яманова Г.А. Сравнительные исследования функционирования дыхательной системы у детей в условиях оздоровительных учреждений // Санитарный врач. - 2021. - № 9. - С. 66-72.

2. Антонова А.А., Сердюков В.Г. Отдых и оздоровление детей и подростков в летних оздоровительных учреждениях Астраханской области // В сборнике: Современные проблемы развития фундаментальных и прикладных наук. Материалы III международной научно-практической конференции. - 2016. - С. 11-16.

3. Антонова А.А., Яманова Г.А., Бабаева А.А., Вазирова Х.М., Хамзатханова А.Х. Организация летнего отдыха и оздоровления детей и подростков Астраханской области // Международный научно-исследовательский журнал. - 2021. - № 9-2 (111). - С. 7-10.

4. Елизарова И.С., Антонова А.А., Сердюкова Т.В., Сердюков В.Г., Сибирякова Н.В., Тыртышная К.В. Динамика состояния здоровья детей и подростков Астрахани // Аллергология и иммунология. - 2012. - Т. 13. - № 1. - C. 101.

5. Сердюков В.Г., Елизарова И.С., Антонова А.А., Шендо Г.Л., Рябикин В.Р. Динамика показателей здоровья детей младшего школьного возраста в Астрахани // Астраханский медицинский журнал. - 2011. -Т. 6. № 3. - С. 291-293.

6. Шумилина, Т.О. Детский оздоровительный лагерь: требования к безопасности организации летнего отдыха детей и подростков // Народное образование. - 2012. - № 3(1416). - С. 15-159.

7. Яманова Г.А., Сердюков В.Г., Антонова А.А., Милюченкова Л.А. Влияние физической нагрузки на состояние опорно-двигательного аппарата кадетов // В сборнике: Структурные преобразования органов и тканей в норме и при воздействии антропогенных факторов. Сборник материалов международной научной конференции, посвященной 80-летию со дня рождения профессора Асфандиярова Растяма Измайловича. Под редакцией Л.А. Удочкиной, Б.Т. Куртусунова. - 2017. - С. 183-184.

8. Яманова Г.А., Давыденко Д.В., Антонова А.А. Гигиеническая оценка эффективности физического воспитания школьников // В сборнике: Неделя науки - 2016. Материалы Всероссийского молодѐжного форума с международным участием. - 2016. - С. 460-463.

9. Яманова Г.А., Сердюков В.Г., Антонова А.А., Милюченкова Л.А., Ширинова 3.Р. Эффективность мониторинга и оздоровления детского населения в образовательной среде // Вестник Волгоградского государственного медицинского университета. - 2021. - № 1 (77). - С. 173-177. 


\section{REFERENCES}

1. Antonova A.A., Jamanova G.A. Sravnitel'nye issledovanija funkcionirovanija dyhatel'noj sistemy u detej v uslovijah ozdorovitel'nyh uchrezhdenij // Sanitarnyj vrach. - 2021. - № 9. - pp. 66-72. (In Russian).

2. Antonova A.A., Serdjukov V.G. Otdyh i ozdorovlenie detej i podrostkov v letnih ozdorovitel'nyh uchrezhdenijah Astrahanskoj oblasti // V sbornike: Sovremennye problemy razvitija fundamental'nyh i prikladnyh nauk. Materialy III mezhdunarodnoj nauchno-prakticheskoj konferencii. - 2016. - pp. 11-16. (In Russian).

3. Antonova A.A., Jamanova G.A., Babaeva A.A., Vazirova H.M., Hamzathanova A.H. Organizacija letnego otdyha i ozdorovlenija detej i podrostkov Astrahanskoj oblasti // Mezhdunarodnyj nauchno-issledovatel'skij zhurnal. 2021. - № 9-2 (111). - pp. 7-10. (In Russian).

4. Elizarova I.S., Antonova A.A., Serdjukova T.V., Serdjukov V.G., Sibirjakova N.V., Tyrtyshnaja K.V. Dinamika sostojanija zdorov'ja detej i podrostkov Astrahani // Allergologija i immunologija. - 2012. - T. 13. - № 1. - pp. 101. (In Russian).

5. Serdjukov V.G., Elizarova I.S., Antonova A.A., Shendo G.L., Rjabikin V.R. Dinamika pokazatelej zdorov'ja detej mladshego shkol'nogo vozrasta v Astrahani // Astrahanskij medicinskij zhurnal. - 2011. -T. 6. № 3. - pp. 291-293. (In Russian).

6. Shumilina, T.O. Detskij ozdorovitel'nyj lager': trebovanija k bezopasnosti organizacii letnego otdyha detej i podrostkov // Narodnoe obrazovanie. - 2012. - № 3(1416). - pp. 15-159. (In Russian).

7. Jamanova G.A., Serdjukov V.G., Antonova A.A., Miljuchenkova L.A. Vlijanie fizicheskoj nagruzki na sostojanie oporno-dvigatel'nogo apparata kadetov // V sbornike: Strukturnye preobrazovanija organov i tkanej v norme i pri vozdejstvii antropogennyh faktorov. Sbornik materialov mezhdunarodnoj nauchnoj konferencii, posvjashhennoj 80letiju so dnja rozhdenija professora Asfandijarova Rastjama Izmajlovicha. Pod redakciej L.A. Udochkinoj, B.T. Kurtusunova. - 2017. - pp. 183-184. (In Russian).

8. Jamanova G.A., Davydenko D.V., Antonova A.A. Gigienicheskaja ocenka jeffektivnosti fizicheskogo vospitanija shkol'nikov // V sbornike: Nedelja nauki - 2016. Materialy Vserossijskogo molodèzhnogo foruma s mezhdunarodnym uchastiem. - 2016. - pp. 460-463. (In Russian).

9. Jamanova G.A., Serdjukov V.G., Antonova A.A., Miljuchenkova L.A., Shirinova Z.R. Jeffektivnost' monitoringa i ozdorovlenija detskogo naselenija v obrazovatel'noj srede // Vestnik Volgogradskogo gosudarstvennogo medicinskogo universiteta. - 2021. - № 1 (77). - pp. 173-177. (In Russian). 